\title{
Lethal Ovitrap CIMATEC: A New Trap for Arbovirus Transmitting Mosquitoes
}

\author{
Eduardo Oyama*; Daniel Mota \\ Health Institute of Technology - SENAI-CIMATEC; Salvador, BA, Brazil
}

\begin{abstract}
A lot of countries have difficulty in combating Ae. aegypti, due to the high adaptability of this mosquito to the urban area. The National Program for Dengue Control (PNCD) is responsible for allocating the most activities to combat Ae. aegypti in districts of Brazil (basic sanitation, education, chemical control). Despite the technological advances in the $21^{\text {th }}$ century, there was little social commitment with the conception of a formal device in the fight against $\mathrm{Ae}$. aegypti. Senai-Cimatec developed a trap (Lethal Ovitrap Cimatec ${ }^{\mathrm{TM}}$ ) based on new technologies to control Aedes aegypti. So, the aim of this study was to compare the traditional traps on the market with the LOC ${ }^{\mathrm{TM}}$ trap, created by Cimatec. We performed two experiments to evaluate the performance of the traps against the mosquitoes. The tests occurred in a monitored and closed environment at the Central Laboratory of Bahia (Entomology Laboratory) (LACEN/BA). The larvae, water, and substrate for the experiment in the three containers had the same origin; three cages were kept in the entomology sector with the same conditions of temperature and humidity. The results showed that LOC $^{\mathrm{TM}}$ has several advantages when compared to the traditional traps, such as: capacity to eliminate the immature forms of the vector in a few hours; entrapment and extermination of larvae and/or adults forms by asphyxiation; high lethality for mosquitoes and ability to reduce the Aedes population in an area by removing from the environment future generations of mosquitoes; installation; it is attractive to mosquitoes; no needs of weekly monitoring; no power consumption; simple manipulation and low-cost; water as a protection factor and not as a risk factor; it does not use insecticide or any toxic agent harmful to human health. So, the use of $\mathrm{LOC}^{\mathrm{TM}}$ has advantages over traditional traps, directing the biotechnology market to new solutions with low-cost, easy to handle and non-toxic to man and the environment in the fight agains Ae. aegypti.
\end{abstract}

Keywords: Traditional Ovitrap. LOC ${ }^{\mathrm{TM}}$. Arboviruses. Ae. aegypti.

The impacts of the current epidemiological scenario of arboviruses in Brazil, characterized by Dengue, the dissemination of ZIKV and CHIKV virus, and the re-emergence of FMV in the ExtraAmazon region were enough to establish a public health emergency by the Ministry of Health and the World Health Organization [1].

Brazil recorded 113,381 suspected cases of Dengue Fever, 43,010 of Chikungunya, 7,911 of ZIKV Fever and 3,140 cases of Yellow Fever according to the Ministry of Health (2017) [2]. In that period, 17 deaths from Dengue, 9 deaths from CHIKV, and 240 deaths from Yellow Wild Fever were confirmed.

Received on 17 February 2019; revised 23 February 2019. Address for correspondence: Dr. Eduardo Oyama. Avenida Orlando Gomes, N. 1845, Piatã. Zip Code: 41650-010. Salvador, Bahia, Brazil. Phone: (+55 71) 3879-5501.E-mail: eduoyama@gmail.com.

J Bioeng. Biotech. Appl. Health 2019;2(2):47-53.

(C) 2019 by SENAI CIMATEC. All rights reserved.
The entomological situation reveals that $A e$. aegypti is found dispersed in most Brazilian cities [3]. The Ministry of Health has tried to implement control actions for this vector; however, the results have not been satisfactory, since infestation by remains high [4]. Only four Brazilian states (Acre, Amapá, Piauí and Sergipe) have not yet registered the presence of Ae. Albopictus [5]. However, most Brazilian states have sufficient Ae. aegypti to initiate and maintain the transmission of DENV and other arboviruses.

A lot of countries have difficulty in combating Ae. aegypti, due to the high adaptability of this mosquito to the urban area [6]. In the last two decades, the intensification of the vector combat has been carried out mainly through chemical control, which has led to a resistance of Ae. aegypti to many groups of insecticides [7]. Therefore, additional effort from the health sector is required, with an estimated cost of $\mathrm{R} \$ 1$ million per day [8]. 
The National Program for Dengue Control (PNCD) is responsible for allocating the most activities to combat Ae. aegypti in the districts of Brazil, such as investment in basic sanitation and education [3], chemical control, and other essential performances [6].

The areas of water accumulation (focal treatment) applied chemical control with larvicidal action. The control of adult insects uses two chemical control modalities: the spraying of insecticides with residual effect in the walls of breeding places, which are susceptible to the proliferation of immature forms (larvae and pupae), denominated perifocal treatment; and the spatial treatment of insecticide by ultralow volume (UVB), indicated for outbreak and epidemic situations [1].

New strategies to combat vectors have been adopted to reduce the population of mosquitoes to minimize the impact of chemical larvicides on human health and in the environment, such as biological control based on the use of natural enemies or biological toxins. Different groups of organisms (bacteria, protozoa, fungi, and viruses) with potential use against Ae. aegypti have been evaluated. Among them, Bacillus thuringiens isisraelensis (B.t.i) and Bacillus sphaericus (B.s.) have been used to control mosquitoes. B.t.i has been used in the control of Ae. aegypti because it is effortless to prepare the formulation and because of the properties that allow its growth on a wide variety of substrates [10].

Environmental management should be considered an equally relevant strategy for mosquitos' controls. Among the ecological management actions, there are the elimination and removal of breeding sites in the home environment, the storage, collection and final disposal of solid waste, control of the border vegetation of the breeding sites, drainage and earth moving services, as well as investment in the primary sanitation system, and the participation and education of the community [11].

More recently, full integration of control alternatives has been devised, combining physical and biological management control: the use of specific adulticides and the application of alternative (natural) larvicides with low impact on human health and in the environment. However, this kind of strategies cannot be dissociated from education of the community to achieve success in combating vector insects [12].

Despite the technological advances in the $21^{\text {th }}$ century, with the use of new machines, materials, and production processes, there was little social commitment with the conception of a formal device in the fight against Ae. aegypti. Little effort was made to create tools, such as traditional traps, to combat the mosquitoes.

Senai-Cimatec developed a trap (Lethal Ovitrap Cimatec $^{\mathrm{TM}}$ ) based on new technologies to control Aedes aegypti.

The aim of this study was to compare the traditional traps on the market with the $\mathrm{LOC}^{\mathrm{TM}}$ trap, created by Cimatec, for the ability to visualize the presence of the eggs and eliminate larval forms of Ae. aegypti.

\section{Traditional Traps}

The traditional oviposition trap consists of a black-plastic container with a large hole (Figure 1). The volume capacity is $300 \mathrm{~mL}$, but only 200 $\mathrm{mL}$ of water is added, equivalent to the size of the LOC $^{\mathrm{TM}}$ trap. The Eucatex palette $-6.0 \mathrm{~cm}$ by $2.5 \mathrm{~cm}$ plywood - is placed inside the trap, similar to that used in $\mathrm{LOC}^{\mathrm{TM}}$.

\section{Lethal Ovitrap Cimatec $^{\mathrm{TM}}\left(\right.$ LOC $\left.^{\mathrm{TM}}\right)$}

The LOC $^{\mathrm{TM}}$ trap is made up of a transparent cylindrical plastic container, containing two pieces: a cap with a recess and a funnel in the center. The cover has three openings, through which the female mosquitoes enter to perform oviposition. Besides being the access door to the vector, the cover protects the trap from objects or other materials that may fall in it and clog it. The funnel is tilted, and the outer wall is roughened to increase egg adhesion because Aedes aegypti 
Figure 1. Traditional Ovitrap.

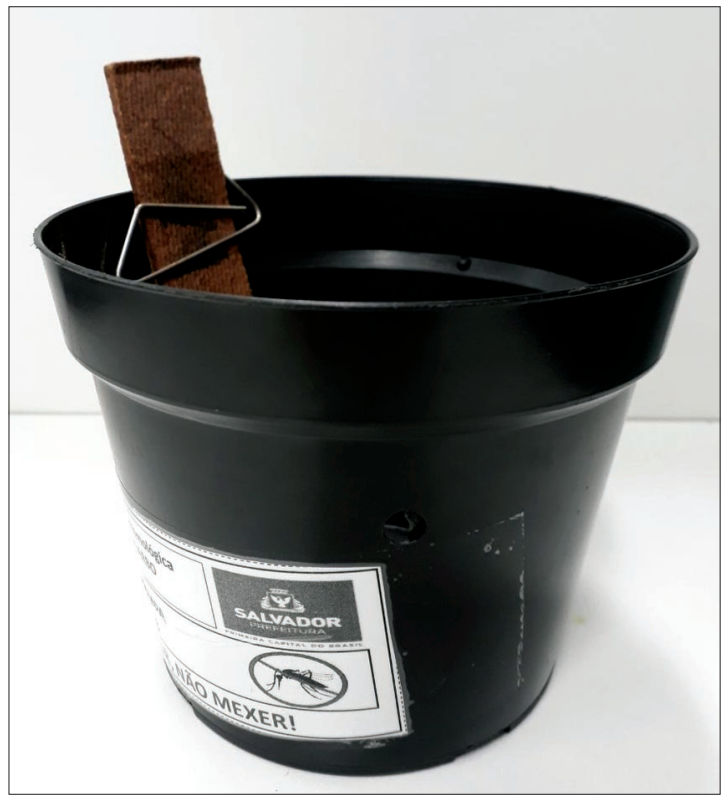

females prefer to lay eggs on rough walls (Figure 2).

The $\mathrm{LOC}^{\mathrm{TM}}$ does not have sensors, light, nor a mechanical barrier nor a physical barrier. There is no card with glue, insecticide, nor a fan and attractive chemicals. It is a simple trap, easy to handle, low-cost and uses no energy in its operation.

The trap is excellent, with a quality certification guaranteed by the responsible institutions, which ensure its long-term durability in combating vectors.

\section{$\underline{\mathrm{LOC}^{\mathrm{TM}}} \stackrel{\text { Operation }}{\mathrm{T}}$}

The Ae. aegypti female deposits the eggs on the wall of the funnel. In contact with the water, the eggs will hatch, and the larvae will emerge. The newborn mosquito larvae descend to the bottom of the container, looking for food passing through the rod. However, the larvae need to return to the surface to breathe, but they cannot reach the top of the rod, which has a $45^{\circ}$ degree inclination and is usually submerged, and get trapped and die by asphyxiation.

When the level of the container is not full, the larvae tend to survive to adult form, but the mosquitoes also cannot get out because they even
Figure 2. LOC trap.

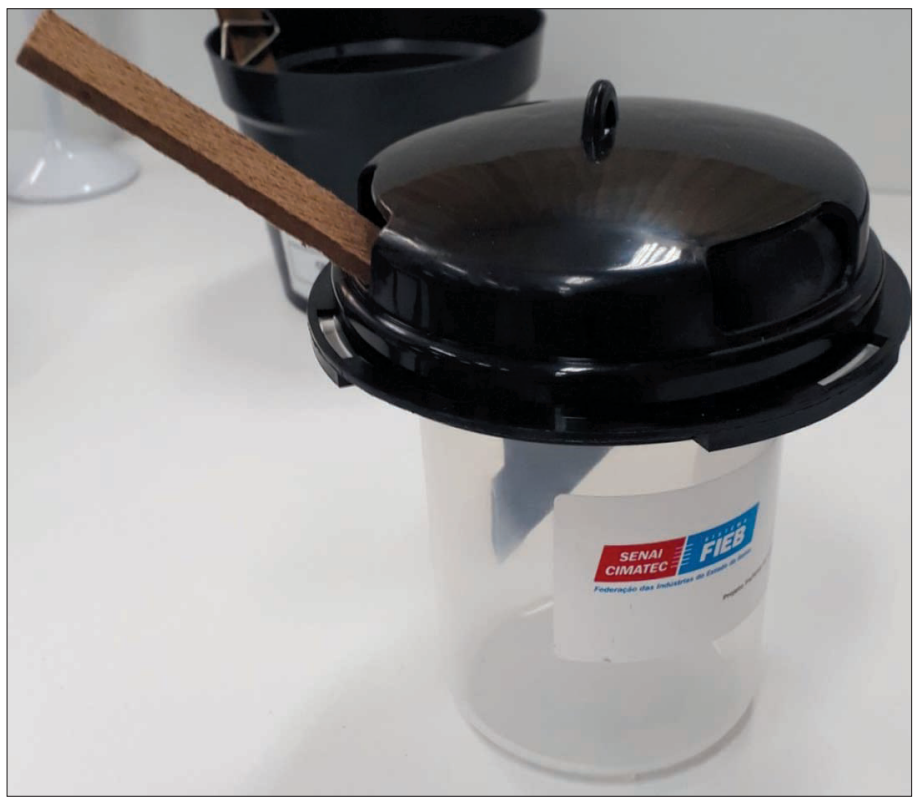

cannot reach the top of the rod, and die inside the container. The cover must be unscrewed to release the water with the dead larvae or insects to remove the dead larvae or adults.

$\mathrm{LOC}^{\mathrm{TM}}$ uses the color black and the presence of water to attract the Culicidae. The females of the Ae. aegypti are invited to the trap and lay the eggs in the funnel. The rounded form and the dark color are considered visual stimuli since they simulate a quiet place to rest for the adult mosquitoes to lay their eggs.

In this trap, any egg that hatches is unable to release the adult mosquito into the external environment due to its internal design. Thus, this trap can reduce the population of Ae. aegypti in urban areas by collecting eggs, trapping larvae and pupae, hampering the emergence of adult mosquitoes.

\section{Installation of $\mathrm{LOC}^{\mathrm{TM}}$}

The trap must be installed at ground level or the height of 1.20 to $1.50 \mathrm{~cm}$ from the floor and can be hung by the handle or under a flat surface, with natural water. The trap should be placed preferably indoors or in the perimeter, in shaded places, protected from direct rain, and with little movement of people or animals. 
$\mathrm{LOC}^{\mathrm{TM}}$ requires that the owner maintain the trap full of water. If the trap is full, it will kill the larvae within a few hours later. On the other hand, if it is partially complete, the larvae will survive, but the adults will die from drowning after exhaustion.

\section{The Experiments}

We performed two experiments to evaluate the performance of the traps against the mosquitoes. The tests occurred in a monitored and closed environment at the Central Laboratory of Bahia (Entomology Laboratory) (LACEN/BA). The larvae, water, and substrate for the experiment in the three containers had the same origin; keeping three cages in the entomology sector with the same conditions of temperature and humidity.

We collected a total of 90 larvae of Culicidae from a single artificial local at LACEN/BA. These larvae were introduced into three (03) traps in separate cages:

Trap 1: Black Hole Trap was filled with water, i.e., no oxygen was available inside for larval breathing. Thirty larvae at different stages $\left(2^{\text {nd }}, 3^{\text {rd }}\right.$, and $4^{\text {th }}$ stages) were introduced. It was observed that the larvae descended immediately through the funnel to the bottom of the container. The trap was placed inside cage 1 to ensure the containment of future adults in case of larvae survival. Larval return to the surface by the funnel was not observed.

Trap 2: Black Hole trap was partially filled with water. Thirty larvae at different stages $\left(2^{\text {nd }}, 3^{\text {rd }}\right.$, and $4^{\text {th }}$ stages) were introduced. The larvae were introduced into the funnel with the help of a pipette, where it was observed that they immediately entered the container. The trap was put into cage 2. The return of the larvae to the surface via the funnel was also not observed.

Trap 3: An open cylindrical pot was partially filled with water, without a funnel. Thirty larvae in $2^{\text {nd }}$, $3^{\text {rd }}$, and $4^{\text {th }}$ stages were introduced. The container was put into cage 3 .
Three cages were used in the laboratory environment. Ten females and two males of $A e$. aegypti were put into each cage. The females were inserted engorged on the exposure date $(01 / 07 / 2016)$. Two oviposition traps were placed within each cage: the traditional ovitrap and the $\mathrm{LOC}^{\mathrm{TM}}$ trap. In both traps, a Eucatex palette was inserted.

Reading for the presence and number of eggs in the palette was performed daily from 07/04 to $07 / 08$ (five days) for one week from the start date of the experiment $(01 / 07 / 2016)$. The time recommended to monitoring the ovitraps in the field. A magnifying glass counted the eggs of the mosquitoes.

In cage one (1), the $\mathrm{LOC}^{\mathrm{TM}}$ had more eggs (48 eggs) in the palette than the traditional ovitrap palette (45 eggs) (Table 1). In cage two (2), the traditional ovitrap had more eggs (122) than the LOC $^{\mathrm{TM}}$ trap (57 eggs) (Table 2). In cage three (3), the LOC ${ }^{\mathrm{TM}}$ trap had more eggs in the palette (147) than the traditional lovitrap (25 eggs) (Table 3 ). In terms of the total number of eggs collected, the LOC $^{\mathrm{TM}}$ trap had more eggs (252) compared to the traditional trap (192) (Table 4).

Water was added to the traps to the limit of the container on the last day of reading $(07 / 08 / 16)$ for the presence and quantification of eggs $(07 / 08)$ to cause the contact of the water with the eggs in the palettes to hatch and release the larvae.

Larvae counting began on 07/04/16. In the three cages of the experiment it was observed that the $\mathrm{LOC}^{\mathrm{TM}}$ trap did not present any live $A e$. aegypti larvae: we counted twenty-two dead $A e$. aegypti larvae in cage 1; fifteen dead Ae. aegypti in $1^{\text {st }}$ stage larvae in cage 2; and fifty-two dead $A e$. aegypti in $1^{\text {st }}$ stage larvae in cage 3 (Table 5).

Cage three (3) presented adult forms of Culicidae, no winged forms of the vector were observed in cages 1 and 2. No Culicidae survived in any of the three cages, indicating that the $\mathrm{LOC}^{\mathrm{TM}}$ worked both full and partially filled with water.

This experiment was repeated in the laboratory to confirm results and then applied in the field, to validate the project and establish final adjustments, completing the design stage. 
Table 1. Number of Aedes aegypti eggs by traps in cage 1 (traditional ovitrap x LOC ${ }^{\mathbf{T M}}$ ).

\begin{tabular}{ccc}
\hline Read Date (Eggs) & Traditional Ovitrap & LOC $^{\mathbf{T M}}$ \\
\hline $07 / 04 / 16$ & 0 & 0 \\
$07 / 05 / 16$ & 0 & 0 \\
$07 / 06 / 16$ & 19 & 16 \\
$07 / 07 / 16$ & 0 & 0 \\
$07 / 08 / 16$ & 26 & 32 \\
\hline Total & $\mathbf{4 5}$ & $\mathbf{4 8}$ \\
\hline
\end{tabular}

Table 2. Number of Aedes aegypti eggs by traps in cage 2 (traditional ovitrap x LOC ${ }^{\mathbf{T M}}$ ).

\begin{tabular}{ccc}
\hline Read Date (Eggs) & Traditional Ovitrap & LOC $^{\text {TM }}$ \\
\hline $07 / 04 / 16$ & 0 & 0 \\
$07 / 05 / 16$ & 0 & 0 \\
$07 / 06 / 16$ & 17 & 15 \\
$07 / 07 / 16$ & 0 & 0 \\
$07 / 08 / 16$ & 105 & 42 \\
\hline Total & $\mathbf{1 2 2}$ & $\mathbf{5 7}$ \\
\hline
\end{tabular}

Table 3. Number of Aedes aegypti eggs by traps in cage 3 (traditional ovitrampa x LOC ${ }^{\text {TM}}$ ).

\begin{tabular}{ccc}
\hline Read Date (Eggs) & Traditional Ovitrap & LOC $^{\text {TM }}$ \\
\hline $07 / 04 / 16$ & 0 & 0 \\
$07 / 05 / 16$ & 25 & 147 \\
$07 / 06 / 16$ & 0 & 0 \\
$07 / 07 / 16$ & 0 & 0 \\
$07 / 08 / 16$ & 0 & 0 \\
\hline Total & $\mathbf{2 5}$ & $\mathbf{1 4 7}$ \\
\hline
\end{tabular}

Table 4. Total of Aedes aegypti eggs by traps (traditional ovitap x LOC ${ }^{\text {TM }}$

\begin{tabular}{ccc}
\hline Cages & Traditional Ovitrap & LOC $^{\text {TM }}$ \\
\hline 1 & 45 & 48 \\
2 & 122 & 57 \\
3 & 25 & 147 \\
\hline Total & $\mathbf{1 9 2}$ & $\mathbf{2 5 2}$ \\
\hline
\end{tabular}

Table 5. Total of Aedes aegypti larvae in LOC ${ }^{\text {TM }}$ traps.

\begin{tabular}{ccc}
\hline Cages & \multicolumn{2}{c}{ LOC $^{\text {TM }}$} \\
\cline { 2 - 3 } & Live larvae & Dead larvae \\
\hline 1 & 0 & 22 \\
2 & 0 & 15 \\
3 & 0 & 52 \\
\hline Total & $\mathbf{0}$ & $\mathbf{8 9}$ \\
\hline
\end{tabular}




\section{Comparison Between $\mathrm{LOC}^{\mathrm{TM}}$ and Traditional Ovitraps}

The $\mathrm{LOC}^{\mathrm{TM}}$ project was carried out in stages dependent on each other, involving literature review, laboratory and field tests, to consolidate a marketable, efficient and compatible product for the needs of the community in the combat of $A e$. aegypti.

The initial phase of the design process included the definition of the problem, a result of the consumer's need. This stage is crucial and decisive for the development of the method. It addressed a current issue in daily life, the incidence of dengue, which persists despite government efforts and campaigns. First of all, a trap to capture dengue vectors was chosen to be redesigned.

The second phase consisted of the analysis of traps existing in the market, i.e., the collection of data on already existing products. The study of all the data collected on commercial traps provided suggestions of what should not be done and what needed to be improved.

Formal studies helped identify alternatives to solve the problem in the phase of alternative models and sketches. Thus, the pre-selected options were analyzed to establish the best set of improvements for the final prototype. We did a study of economic feasibility and sale price after selecting the best alternative that fully met consumer needs and project specifications, and in parallel, the drawings for the construction of the prototype.

In the fight against Ae. aegypti and Aedes albopictus, no trap is recommended by the National Program for Dengue Control. There is also no commercially available trap sufficiently capable of decreasing the vector population and thus reducing dengue transmission. The trap created by our group from Cimatec (Lethal Ovitramp Cimatec $^{\mathrm{TM}}$ ) is better than traditional traps on the market.

The $\mathrm{LOC}^{\mathrm{TM}}$ is a trap that can also be used in monitoring and early detection of Dengue and Yellow Fever vectors, such as larval traps (larvae trap) and ovitraps (egg traps). LOC $^{\mathrm{TM}}$ is a lethal trap with a function to reduce the Aedes population in the environment and future generations of mosquitoes.

If compared to the traditional ovitrap, as our study showed, it contains functional and aesthetic improvements. One of the main differentials of this trap is the angle in the nozzle of the funnel, which is the main item responsible for the dispensing with the sieve. As a result, the constant handling of the trap is not required, reducing the risk of mishandling and malfunctioning.

Existing traps in the market were essential in aiding the design of $\mathrm{LOC}^{\mathrm{TM}}$. For example, we mention the funnel, which is located above the trap in the $\mathrm{LOC}^{\mathrm{TM}}$, so the volume of water in the trap causes the death of the captured larvae in only a few hours. $\mathrm{LOC}^{\mathrm{TM}}$ can, therefore, reduce Aedes vectors, which can have a huge impact on public health.

$\mathrm{LOC}^{\mathrm{TM}}$ has several advantages when compared to the traditional traps, such as: capacity to eliminate the immature forms of the vector in a few hours; entrapment and extermination of larvae and/or adults forms by asphyxiation; high lethality for mosquitoes and ability to reduce the Aedes population in an area by removing from the environment future generations of mosquitoes; installation, since it can be installed in different contexts and at different heights; it is attractive to mosquitoes - dark color of cover and funnel, and presence of water; no needs to be monitored weekly; no power consumption; simple manipulation and low-cost; water as a protection factor and not as a risk factor; it does not use insecticide or any toxic agent harmful to human health.

So, the use of $\mathrm{LOC}^{\mathrm{TM}}$ has advantages over traditional traps, directing the biotechnology market to new solutions with low-cost, easy to handle and non-toxic to man and the environment in the fight agains Ae. aegypti.

\section{References}

1. Donalisio, M.R., Freitas, A.R., Von Zuben A.P.B. Arboviroses emergentes no Brasil: desafios para a clínica e implicações para a saúde pública. RevSaude Publica. 2017; 51: 30 . 
2. Ministério da Saúde (BR). Boletim Epidemiológico Secretaria de Vigilância em Saúde. Monitoramento dos casos de dengue, febre de chikungunya e febre pelo vírus Zika até a Semana Epidemiológica 15, Volume $48 \mathrm{n}^{\circ} 14$, Brasília: Ministério da Saúde; 2017.

3. Brasil. Ministério da Saúde. Relatório sobre a Dengue. Brasília, 2010.

4. Brasil. Ministério da Saúde. Fundação Nacional de Saúde.Programa Nacional de Controle da Dengue (PNCD). 2a ed. Brasília, 2002, 32p.

5. Aguiar, D.B. et al. Primeiro registro de Aedes albopictus (Diptera: Culicidae) em Roraima, Brasil. Acta Amazônica 2008;38(2):357-60.

6. Teixeira, M.G., etal. Sentinel areas: Public Health surveillance strategy. Cadernos de Saúde Pública 2002;18(5): 1189-95.

7. Brogdon, W.G., McAllister, M. Insecticide resistance and vector control. Emerging Infectious Disease 1998;4:605-13.
8. Brasil. Ministério da Saúde. Fundação Nacional de Saúde. Programa Nacional de Controle da Dengue (PNCD). $2^{\mathrm{a}}$ ed. Brasília: Fundação Nacional de Saúde, 2005.

9. Ministério da Saúde. Secretaria de Vigilância em Saúde. Dengue no Brasil. Informe Epidemiológico, Brasília, novembro de 2009, 10p.

10. Gubler, D.J. Epidemic Dengue/Dengue hemorrhagic fever as a public health, social and economic problem in the $21 \mathrm{st}$ century. Trends Microbiol. 2002;10:100-3.

11. Andrade, C.S.F., Brassolatti R.C., Santos, L.U. Educação para o manejo integrado dos vetores da dengue. Manual UNICAMP. Campinas, 36pp.1998.

12. Axtell, R.C. Principles of integrated pest management (IPM) in relation to mosquito control. Mosquito News 1979;39(4): 709-18. 